\title{
CLINICAL ASSESSMENT OF 324 BREAST CANCER CASES IN TWO CENTERS BETWEEN THE YEARS OF 1992 AND 2002
}

\author{
Ali Borazan', Hasan Üstün², Faruk Aksoy ${ }^{3}$, Celalettin Vatansev ${ }^{3}$,Zafer Cantürk ${ }^{4}$, Muharrem Akkaş ${ }^{1}$, \\ Şamil Ecirli ${ }^{5}$, Ahmet Yulmaz ${ }^{1}$
}

Kocaeli University, Faculty of Medicine; Department of Internal Medicine ${ }^{1}$, Department of Medical Oncology ${ }^{2}$, Department of General Surgery ${ }^{4}$; Selcuk University, Faculty of Medicine; Department of General Surgery ${ }^{3}$, Department of Internal Medicine ${ }^{5}$

Summary: The records of the 324 patients with breast cancer; diagnosed and followed in two different University Hospital between years of January 1992 and January 2002 were reviewed retrospectively. The median age of the patients was $49.0 \pm 12.5$ years, with the range of 18 and 90 years. The most frequently seen age interval of the patients was 40 and 49 years. The most frequently seen symptom and physical examination finding of the patients were breast mass. Breast cancer was diagnosed in 324 women, 173 in the left breast and 151 in the right breast. At the hospital admission percentages of the patients' disease stages were as follows: I (2.8 \%), IIA (30.0 \%), IIB (24.0 \%), IIIA (19.8 \%), IIIB (11.4) and IV (12.0 \%). The most frequently seen histopathological diagnosis was infiltrative ductal carcinoma (84.4 \%). Axillary lymph node metastasis was found in $61.7 \%$ of the patients. Primary therapeutic options and percentages were surgical therapy (78.5\%), systemic chemotherapy (17.5\%) and radiotherapy (4\%). Systemic chemotherapy was given to $81.2 \%$ of the patients. From the files, estrogen receptor status was known in 311 and positive in 128 (41.2\%) of them. Tamoxifen was given patients who had positive estrogen receptor. The five-year survival rate of the patients was calculated as $75.9 \%$.

Key words: Breast cancer; Stage; Treatment; Survival

\section{Introduction}

Today breast cancer is the most commonly seen cancer among women. The death due to breast cancer among women comes as the second leading cause after lung cancer. The risk of developing breast cancer is one in eight women in developed countries (1).

There are more than 1,000,000 breast cancer cases each year, and almost half of these are in less developed countries (20).

In the United States of America (USA) the rate of breast cancer and other cancers increased between 1973 and 1990. All-sites cancer incidence and mortality fell in the period 1991 through 1995. After the rapid increase in breast cancer incidence rates that accompanied the widespread introduction of the mammography in the 1980 s, breast cancer mortality is now decreasing at a rate of approximately $1 \%$ per year (16).

There is not enough information about cancer statistics and outcomes for our country. In this study we aimed to analyze breast cancer cases retrospectively followed in two different University Hospital in Turkey within the last ten years.

\section{Patients and methods}

The records of women with diagnosis of breast cancer that followed in Hospitals of Selcuk University and Kocaeli University were examined in a retrospective way. The age of the patients, their first complaints or symptoms, physical examination findings, used diagnostic methods, localization of the tumors, axillary lymph node status, histopathological types of the tumors, clinical stages and survival periods of the patients were recorded.

\section{Results}

The median age of the cases was $49.0 \pm 12.5$ (range: 18-90 years) and distribution according to the age groups are shown in Table 1. Breast cancer was observed more common in the patients between the ages of 40-49 (32.5\%).

Generally the patients $(80.8 \%)$ were admitted to the hospital as a result of the lump in the breast. The lumps were painless in most of the cases $(80.9 \%)$. The other complaints of the patients are shown in Table 2 .

While mass was palpated in 275 (85\%) cases, axillary lymph nodes were palpated only in 174 (50 \%) cases. Peau 
D’orange appearance and nipple retraction were seen in 44 (13.6\%) and 27 (8.3\%) cases, respectively. Physical examination findings of the patients are shown in Table 3.

Tab. 1: The distribution of the cases according to the age groups.

\begin{tabular}{|c|c|c|}
\hline Age & Number of the cases & $\mathbf{\%}$ \\
\hline $0-29$ years & 9 & 2.8 \\
\hline $30-39$ years & 51 & 15.7 \\
\hline $\mathbf{4 0 - 4 9}$ years & $\mathbf{1 0 5}$ & $\mathbf{3 2 . 5}$ \\
\hline 50-59 years & 80 & 24.7 \\
\hline 60-69 years & 61 & 18.8 \\
\hline $70-79$ years & 16 & 4.9 \\
\hline $80-89$ years & 1 & 0.3 \\
\hline 90+ years & 1 & 0.3 \\
\hline Total & 324 & 100.0 \\
\hline
\end{tabular}

Tab. 2: The clinical symptoms of the patients at hospital admission.

\begin{tabular}{|c|c|c|}
\hline Symptoms & Number of the cases & $\mathbf{\%}$ \\
\hline Lump within the breast & $\mathbf{2 6 2}$ & $\mathbf{8 0 . 9}$ \\
\hline Breast pain & 91 & 28.1 \\
\hline Axillary swelling & 69 & 21.3 \\
\hline Pain in axillary region & 63 & 19.4 \\
\hline Discharge from the nipple & 27 & 8.3 \\
\hline Ulcerous wound & 18 & 5.6 \\
\hline Swelling and/or pain of breast & 11 & 3.4 \\
\hline Nipple retraction & 16 & 4.9 \\
\hline Back pain & 3 & 0.9 \\
\hline
\end{tabular}

Tab. 3: Physical examination findings of the patients at hospital admission.

\begin{tabular}{|c|c|c|}
\hline Findings & Number of the cases & \% \\
\hline Lump within the breast & 275 & 84.9 \\
\hline Axillary mass & 174 & 50.0 \\
\hline Peau D’orange & 44 & 13.6 \\
\hline Retracted nipple & 27 & 8.3 \\
\hline Diffuse swelling of the breast & 10 & 3.1 \\
\hline Supraclavicular mass & 14 & 4.0 \\
\hline Hepatomegaly & 6 & 1.9 \\
\hline Edema of upper extremity & 5 & 1.5 \\
\hline Ascitis & 4 & 1.2 \\
\hline Satellite nodule & 4 & 1.2 \\
\hline
\end{tabular}

Tab. 4: Clinical staging of the patients according to TNM classification.

\begin{tabular}{|c|c|c|}
\hline Stage & Number of the cases & \% \\
\hline I & 9 & 2.8 \\
\hline IIA & 98 & 30.2 \\
\hline IIB & 78 & 24.0 \\
\hline IIIA & 64 & 19.8 \\
\hline IIIB & 37 & 11.4 \\
\hline IV & 38 & 12.1 \\
\hline Total & 324 & 100.0 \\
\hline
\end{tabular}

Tab. 5: Tumor localization in breast cancer patients.

\begin{tabular}{|c|c|c|c|c|}
\hline Localization & Right & Left & Total & \% \\
\hline Areola & 23 & 30 & 53 & 16.4 \\
\hline Upper exterior & 73 & 80 & 153 & 47.2 \\
\hline Upper interior & 23 & 25 & 48 & 14.8 \\
\hline Lower exterior & 19 & 17 & 36 & 11.1 \\
\hline Lower interior & 9 & 14 & 23 & 7.1 \\
\hline Diffuse & 4 & 7 & 11 & 3.4 \\
\hline Total & 151 & 173 & 324 & 100.0 \\
\hline
\end{tabular}

Tab. 6: Performed surgical operation procedures in breast cancer patients.

\begin{tabular}{|c|c|c|}
\hline Surgical operation & Number of the cases & \% \\
\hline $\begin{array}{c}\text { Modified Radical Mastectomy } \\
\text { and axillary dissection }\end{array}$ & 216 & 85.7 \\
\hline $\begin{array}{c}\text { Simple mastectomy } \\
\text { and axillary dissection }\end{array}$ & 15 & 5.9 \\
\hline Simple mastectomy & 12 & 4.8 \\
\hline $\begin{array}{c}\text { Partial mastectomy } \\
\text { and axillary dissection }\end{array}$ & 5 & 1.9 \\
\hline Partial mastectomy & 2 & 0.8 \\
\hline Lump excision & 2 & 0.8 \\
\hline Total & 252 & 100.0 \\
\hline
\end{tabular}

Tab. 7: Histopathological diagnosis of the patients.

\begin{tabular}{|c|c|c|}
\hline Histopathological type & Number of the cases & \% \\
\hline Infiltrative ductal carcinoma & 273 & 84.4 \\
\hline Lobular carcinoma & 38 & 11.7 \\
\hline $\begin{array}{c}\text { Mucinous adenomatous } \\
\text { carcinoma }\end{array}$ & 4 & 1.2 \\
\hline Medullary carcinoma & 3 & 0.9 \\
\hline Inflammatory carcinoma & 4 & 1.2 \\
\hline Comedo carcinoma & 1 & 0.3 \\
\hline Papillary carcinoma & 1 & 0.3 \\
\hline Total & 324 & 100.0 \\
\hline
\end{tabular}

According to TNM classification the most commonly seen stage was IIA, 98 cases $(30.2 \%)$ and followed by IIB, 78 cases $(24.0 \%)$. The clinical stages of the patients according to TNM classification are shown in Table 4.

Complete blood count and biochemical parameters including electrolytes, liver and renal function tests were checked in all cases. Co morbid diseases like hypertension in $58(17.9 \%)$ cases, heart disease in $7(2.2 \%)$, diabetes mellitus in $15(4.6 \%)$ cases, gallbladder stone in $7(2.2 \%)$ cases, anemia in 35 (10.8\%) cases, renal insufficiency in one case and Parkinson disease in one case were recorded. Elevated liver function tests in 20 cases $(6.2 \%)$ and hypercalcaemia in 12 (3.7\%) cases were established.

Bilateral mammography, abdominal ultrasonography and chest X-ray were done in all cases and computed tomography of thorax and abdomen were done in necessary situations. Scintigraphy of all bones in the body were taken 
in $87(26.9 \%)$ cases in whom bone metastasis were suspected. Cranial tomographies of eight $(2.5 \%)$ cases were taken due to the suspicion of brain metastasis. The exact diagnosis of breast cancer was established histopathologically in all cases. For this purpose fine needle aspiration in $15(4.6 \%)$ cases and open biopsy in the rest of the cases were done. Diagnoses were established in 12 (3.7 \%) cases with frozen section during operation.

At the first examination distant metastasis were found only in $38(12.1 \%)$ patients. Metastasis locations were found as bone in 11 cases, supraclavicular region in 11 cases, liver in 10 cases, lung in 3 cases, both liver and lung in 2 cases and both liver and bone in 2 cases. The tumor mass localizations were more in the left breast of the patients (53.4\%). When the all quadrants examined the tumors were established mostly in upper external quadrants of the breasts $(47.6 \%)$. The second most often established localization of the tumors was beneath areola region (16.4\%). In 73 of the cases $(22.5 \%)$ clinically inoperable breast cancer were present. After the biopsy, neoadjuvant systemic chemothrerapy was given to 60 cases and 12 cases were referred to radiotherapy (RT) first. Initial surgical procedure and then systemic chemotherapy was applied to the rest of the $252(77.8 \%)$ cases. As systemic chemotherapy CMF (Cyclophosphamide, Methotrexate, 5-Fluorouracil) or CAF (Cyclophosphamide, Adriablastina, 5-Fluorouracil) were given to $81.2 \%$ of the patients according to breast cancer stage and patient's clinical situation. Tamoxifen was given to the patients in whom estrogen receptor positivity shown in breast biopsy specimen. Modified radical mastectomy and axillary dissection were performed in 216 (85.7 \%) patients as the most frequent surgical operation procedure. Performed surgical operations to the patients are shown in Table 6 . In 13 cases $(4.0 \%$ ) surgical operations were performed after down staging of the cancer by neoadjuvant chemotherapy or radiotherapy.

In 273 cases $(84.4 \%)$ infiltrative ductal carcinoma and in 38 cases $(11.7 \%)$ lobular carcinoma were diagnosed histopathologically. Histopathological results of the tumors are shown in the Table 7. In three cases in which infiltrative ductal carcinoma was diagnosed (1\%) also Pagets disease were found at the nipples of the breasts. Axillary dissection was done in 236 cases and metastases were found in 201 of them.

Primary surgery was performed in $76.5 \%$ of the patients, systemic chemotherapy was given to $19.5 \%$ of the patients and radiotherapy was employed to $4 \%$ of the patients. Estrogen receptor status was positive in 41.16 of the cases. Tamoxifen was given to the patients as $20 \mathrm{mg} /$ day in whom estrogen receptor status was found as positive.

One or more postoperative complications was developed in $70(21.6 \%)$ cases and the most frequent complication was seroma and seen in $69(21.3 \%)$ cases. The other complications were skin necrosis in $29(8.9 \%)$ cases, infection of incision line in 15 (4.6) cases and nerve damage in $15(4.6 \%)$ cases.
We were able to contact with the patients or relatives through the telephone and recorded the last visits of the patients from the files. It was seen that $246(75.9 \%)$ patients were still alive and 78 (24.1\%) patients were died during 5 years period. When the died patients analyzed according to the their clinical stages at admission; it was found out that 4 of them in stage IIA, 5 of them in stage IIB, 7 of them in stage IIIA, 9 of them in stage IIIB, 53 of them in stage IV.

\section{Discussion}

Breast cancer is the second most frequent cause of cancer death among women and accounts for $15 \%$ of all cancer deaths among women; only lung cancer causes more deaths (11). It is assumed that in year 2000 one million new cases and over 400,000 deaths would appear in the world (8). The American Cancer Society estimated that 192,000 cases and 40,000 deaths would occur among U.S. women during 2001 (13). Although the frequency of breast cancer varies from region to region, in recent years there is a significant increase in allover the world (8). Difference in the frequency of breast cancer between the developed and rest of the world have decreased. USA, Canada, Spain, and Sweden were countries in which breast cancer is highest. As one of the leading cause of cancer death among all women worldwide, breast cancer accounted for more than 300,000 deaths In 1990: 174,100 deaths occurred in developed countries and 139,500 occurred in developing countries (21). Death rates due to breast cancer were low in Asia, Africa and central America; intermediate in South America and southern Europe; and highest in western Europe and North America (13). This difference is most significant among the women after menopause. Likewise, there are differences between the different ethnic groups.

Probability of having breast cancer and dying from it for an American woman is calculated as $10 \%$ and 3-4 \% respectively. This assessment was approximated between the birth and 110 years old. It is known that the illness increases with the age. Breast cancer is rare in woman younger than 30 year-old, however rapidly increases after these ages. Although there is a slight decrease through the menopause period, following these years slow but an increasing tendency is seen (22). These differences are related to the effects of the environment, life styles, and socio-economical conditions of the women $(9,19)$.

In our study group, most of the patients were between the ages of 40-49 (30.9\%). Genetical, environmental, hormonal, sociological and psychological factors have effect on breast cancer development $(9,14)$. Socio-cultural levels of women have an important role in mortality of the breast cancer patients. The high stage level is more prevalent in low educated people and high rate of death is observed among them $(4,24)$.

The frequency of breast cancer rises two-three times in women who have relative with breast cancer. This risk is doubled if the mother had history of breast cancer and 2.5 
times greater if their sisters had the disease. The existence of cancer in one breast, early menarche, late menopause, late first pregnancy age, being subjected to radiation, obesity, extreme alcohol intake, high fatty diet have been researched risk factors for breast cancer $(3,17)$. Because of the inadequate records and laboratory results of our patients, the role of these factors could not be established in this study. The association of breast cancer with pregnancy is rare. It is defined as the occurrence of breast cancer during pregnancy or during the year following delivery (15). In our series, a case with inoperable breast cancer was diagnosed and referred for chemotherapy and another had a history of full term childbirth of 4 months ago and breast mass complaint during the third trimester of the pregnancy.

The leading first complaint of our breast cancer patients was painless and hard lump within the breast. In addition to breast lump, skin changes like orange peel appearance, satellite nodules, ulceration, nipple discharge, lesions similar to eczama, lymph nodes in axillary and supraclavicular regions were found in clinical examination of the patients. In our patients lump within the breast and lymph nodes in axillary region could be palpated in $86 \%$ and $53 \%$ of the cases, respectively, by physical examination.

Breast cancer was diagnosed more often in upper exterior quadrant $(47.2 \%)$ and beneath the areola region (16.4\%). The excessive breast mass in upper exterior quadrant and connection point of the nipples are the reasons for this distinction pattern.

According to the clinical stage, the most common one stage IIA (30.2 \%) and the least one stage I (2.8\%) in our patients. It was established that $74 \%$ of the cases had one of the stages of IIA, IIB or IIIA. Seventy-two cases $(23.5 \%)$ were assessed as inoperable.

Established prognostic and predictive factors in breast cancer patients are age, race, tumor size, nodal status, tumor subtype, standard pathological grade, estrogen receptor, progesterone receptor, mitotic rate (1). The standard prognostic factors that are used in treatment of the breast cancer are the status of axillary lymph nodes, histological subtype, the tumor size, nuclear and histological grade, the presence of estrogen and progesterone receptors, the measurement of the proliferation. It was stated that the other factors other than these has no clinical benefit (18).

Axillary region is the main drainage area for the breast. In the $50 \%$ breast cancer cases that are diagnosed clinically, axillary lymph node metastasis was observed histopathologically. The status of axillary lymph node metastasis is not directly related to the dimension of the primary tumor. Even in the small tumors like $0.5 \mathrm{~cm}$ diameter, the risk of axillary lymph node metastasis is as $20 \%$. Localization of the tumor within the breast helps to determine the risk of axillary lymph node metastasis. It was known that tumors of external quadrant cause the axillary lymph node metastasis more than one of internal quadrant. In addition, it was shown that the number of the lymph nodes with metastasis is independent from the size of the tumor and directly re- lated to disease outcome $(6,23)$. Axillary lymph node metastasis in our patient group was found out as $66.7 \%$. This number is apt with the data in the literature.

In early postoperative period the most common morbidity was found as seroma in the patients $(22.4 \%)$. Other complications of our cases were appropriate with the literature knowledge.

Surgical treatment, systemic chemotherapy, radiotherapy, hormonal therapy can be used for treatment of breast cancer. One of these treatment options or combinations might be preferred according to the patient's clinical status, tumor stage and characteristics of the tumor. It has been advised to use Tamoxifen in all estrogen-receptor-positive premenopausal and post-menopausal women $(2,5,7,10,12)$. Primarily $76.5 \%$ of our patients were undergone surgery, $19.5 \%$ undergone systemic chemotherapy and $4 \%$ undergone through radiotherapy. Surgical procedure was performed in $4 \%$ of the cases after neoadjuvant chemotherapy or radiotherapy in whom down staging was achieved. After the surgery, systemic chemotherapy was given to 81.2 of the cases. Estrogen-receptor was found positive in 41.16 of the cases and Tamoxifen was given to them as hormonal therapy.

Five-year relative survival rates of breast cancer patients improved from $75 \%$ during mid-1970s to $86 \%$ during 1990 s. Survival rates varied markedly by stage at diagnosis, from $89 \%$ or more in women with localized disease to $22 \%$ or less in women whose tumors have distant spread (13). In our cases, 5-year relative survival rate was found as $75.9 \%$. Breast cancer screening is not established in our country. So that the number of breast cancer patients with early stages is lesser than the patients with higher stages in our series. The patients apply to the hospitals when the disease has been progressed and give more complaints to them.

\section{Conclusion}

As a conclusion it can be predicted that breast cancer, as in the world generally, show the tendency of increase in our country and in our region. The object must be to go beyond the predictions with the real data and analyze the situation we are in, know the risk factors well and enlighten the people under the threat of this disease. The small number of the cases, which diagnosed in early stage shows that breast cancer is not yet well known by the people (especially women) in the region. The aim of this study is to put down the insufficiency in this matter. We are in the opinion that information and data insufficiency would be put away with the countrywide studies about breast cancer.

Both international and intranational breast cancer incidences and mortality rates are different. Incidence rate differences between countries show the importance of inherent genetic risk in breast cancer etiology and lifestyle factors can dramatically affect risk. Incidence rate differences within countries arise in part because of differential access to and utilization of health care resources such as 
screening and diagnosis. We should extend therapeutic advances to all segments of the population.

\section{References}

1. Aapro MS. Adjuvant therapy of primary breast cancer: A review of key findings from the $7^{\text {th }}$ international conference, St. Gallen, February 2001. The Oncologist 2001;6:376-85.

2. Aebi $\mathrm{S}$, Gelber $\mathrm{S}$, Castiglione-Gertsch $\mathrm{M}$ et al. Is chemotherapy alone adequate for young women with oestrogen-receptor-positive breast cancer? Lancet 2000;355:1869-74

3. Anderson DE. Breast: Genetic study of breast cancer: Identification of a high risk group. Cancer 1974;34:1090-7

4. Baquet $\mathrm{CR}$, Commiskey P. Socioeconomic factors and breast carcinoma in multicultural woman. Cancer 2000;88:1256-64.

5. Cardosa F, Di Leo A, Lohrisch C et al. Second and subsequent lines of chemotherapy for metastatic breast cancer: what did we learn in the last two decades? Ann Oncol 2002;13:197-207.

6. Carter C, Allen C, Henson D. Relation of tumor size, lymph node status and survival in 24.740 breast cancer cases. Cancer 1989;63:181-7.

7. Cuzick J. A brief review of the current breast cancer prevention trials and proposals for future trials. Eur J Cancer 2000;36:1298-302.

8. Forbes JF. The control of breast cancer: the role of tamoxifen. Semin Oncol 1997;24(1Suppl 1):S1-5-S1-19.

9. Freeman HP. Cancer in economically disadvantaged. Cancer 1989;64(1Suppl 1): 324-34; discussion 342-345

10. Goldhirsch A, Glick JH, Gelber RD et al. Meeting highlights: International Consensus Panel on the Treatment of Primary Breast Cancer-V Update 1998. J Natl Cancer Inst 1998;90:1601-8.

11. Greenlee RT, Murray T, Bolden S et al. Cancer statistics, 2000. CA Cancer J Clin 2000;50:7-33

12. Hortobagyi GN. Treatment of breast cancer. N Engl J Med 1998;339:974-84.20

13. Lacey JV Jr, Devesa SS, Brinton LA. Recent trends in breast cancer incidence and mortality. Env Mol Mutagenesis 2002;39:82-8.

14. Martin AM, Weber BL. Genetic and hormonal risk faktors in breast cancer J Natl Cancer Inst 2000;92:1126-35.
15. Mathieu E, Merviel P, Barranger E et al. Breast cancer and pregnancy: review of the literature. J Gynecol Obstet Biol Reprod (Paris) 2002;31:233-42.

16. McKean-Cowdin R, Feigelson HS, Ross RK et al. Declining cancer rates in the 1990s. J Clin Oncol 2000;18:2258-68.

17. Morrison AS, Brisson J, Khalid N. Breast cancer incidence and mortality in the Breast Cancer Detection Demonstration Project. J Natl Cancer Inst 1988;80: 1540-7.

18. National Institute of Health Consensus Development Conference Statement: Adjuvant therapy for breast cancer, November 1-3, 2000. J Natl Cancer Inst 2001;93:979-89.

19. Parkin DM, Pisani P, Ferlay J. Estimates of the worldwide incidence of 25 major cancer in 1990. Int J Cancer 1999;80:827-41.

20. Peto R, Boreham J, Clark M et al. UK and USA breast cancer deaths down $25 \%$ in year 2000 at ages 20-69 years. Lancet 2000;355:1822.

21. Pisani P, Parkin DM, Bray F, Ferlay J. Estimates of the worldwide mortality from 25 cancers in 1990. [published erratum. Int J Cancer 83:18-29;1999]. Int J Cancer 1999;83:870-3

22. Seidman H, Mushinski MH, Gelb SK, Silverberg E. Probabilities of eventually developing or dying of cancer. United States CA Cancer J Clin. 1985;35 36-56.

23. Smith J, Gamez-Araujo JJ, Gallager HS et al. Carcinoma of the breast: Analysis of total lymph node involvement versus level of metastasis. Cancer 1977; 39:527-32.

24. Wingo PA, Ries LA, Rosenberg HM, et al. Cancer incidence and mortality, 1973-1995: a report card for the U.S. Cancer 1998:82:1197-207.

Submitted May 2003.

Accepted July 2003.

Hasan Üstün, M.D., Harpsundsvägen 9, 2tr, 12458 Bandhagen (Stockholm), Sweden. e-mail: ustunhtr@hotmail.com 